\title{
O ENSINO DE FILOSOFIA: A LEITURA E O ACONTECIMENTO
}

\author{
Ricardo Nascimento FABBRINI ${ }^{1}$
}

- RESUMO: O curso de filosofia deve desenvolver no aluno uma habilidade técnica na interpretação de diferentes modalidades discursivas - análoga ao "exercício de escuta", no sentido psicanalítico - que lhe permita a experiência da "dominação intelectual": da posse, ainda que provisória, de uma "língua da segurança" que coloque em "suspensão" os "lugares de conversação". Quebrando a barreira entre os gêneros dos discursos, entre as diferentes disciplinas, e entre os diversos interlocutores, o curso de filosofia - seja na universidade, no ensino médio e mesmo fora dos cursos regulares - poderá, desse modo, estimular a produção de um diálogo intenso, laicizado, entre múltiplos sujeitos de enunciação, contribuindo para a constituição do "espaço público". Somente assim a filosofia conquistará definitivamente entre nós, sua madureza.

- PALAVRAS-CHAVE: Filosofia; educação; ensino; Lyotard; Derrida.

\section{A leitura filosófica}

O professor de filosofia deve ensinar "Filosofia": mas, qual filosofia? - ou ainda: "Qual a especificidade dessa "disciplina"? A filosofia, segundo Jean-François Lyotard (1993, p.117), "não é um terreno recortado na geografia das disciplinas". "E se não há conteúdos básicos e métodos fixados - como mostra Celso Fernando Favaretto (1995) - o que deve ser considerado o mínimo necessário para realizar uma suposta

1 Departamento de Filosofia - Pontifícia Universidade Católica - São Paulo - SP. 
especificidade em termos de seu ensino?". ${ }^{2}$ Examinarei, ainda que brevemente essa questão, para então perguntar se a filosofia permanece vinculada - mesmo que apenas no plano do imaginário - à idéia de "formação" (Bildung) no sentido "iluminista" de preparação do cidadão para a "República".

Nunca acreditei, dizia Gérard Lebrun (1976, p.148-53), que um estudante pudesse orientar-se para a filosofia porque tivesse sede de verdade: a fórmula é vazia. É de outra coisa que o jovem tem necessidade: falar uma língua da segurança; instalar-se num vocabulário que se ajuste ao máximo às dificuldades (no sentido cartesiano); munir-se de um repertório de topoi - em suma, possuir uma retórica que lhe permitirá a todo instante denunciar a 'ingenuidade' do 'cientista' ou a 'ideologia' de quem não pensa como ele. Qual melhor recurso se lhe apresenta senão tomar emprestado um discurso filosófico?

Nesse sentido é preciso ressaltar que cabe ao professor colocar o aluno em contato com diferentes modalidades discursivas. "Qualquer que seja o programa escolhido - ética, estética, filosofia política - não se pode esquecer que a leitura filosófica retém o essencial da atividade filosófica" (Favaretto, 1995, p.80); ou ainda: "É preciso acentuar que uma leitura não é filosófica apenas porque os textos são tidos por filosóficos - ou porque seus autores são considerados autores da história da filosofia, de Platão a Sartre -, uma vez que se pode ler textos filosóficos sem filosofar e ler textos considerados artísticos, políticos, jornalísticos filosoficamente" (Lyotard, 1993, p.117). Em outros termos: o que faz da leitura de um texto uma atividade filosófica não é a natureza disciplinar do texto lido, mas o modo como o leitor lê este texto; ou seja, o essencial dessa atividade está no modus operandi do leitor face às diferentes formas de enunciação.

A "leitura filosófica" não se esgota, assim, na simples aplicação de metodologias de leituras. "Ela é um 'exercício de escuta', num sentido análogo ao da psicanálise, pois se manifesta como uma "elaboração do texto que desdobra seus pressupostos e subentendidos" (Favaretto, 1995, p.81). É nesse sentido que, segundo Jean-François Lyotard (1983, p.9-21) a "leitura filosófica" permite que o leitor se transforme na leitura, pois interfere nos modos habituais da recepção"; ou, como dizia Gilles-

2 Esse texto deve muito às reflexões de Celso Fernando Favaretto (1995; 2004) e Renato Janine Ribeiro (2003); retomamos também, a propósito do tema, nosso texto sobre o ensino de filosofia no $2^{\circ}$ grau (Fabbrini, 1995) 
Gaston Granger (1989, p.220), em sentido semelhante, a "leitura filosófica" "é uma atividade produtiva que reconstrói um imaginário oculto, sob a literalidade do texto".

É este trabalho com a linguagem que deve ser ensinado nos cursos de filosofia, ou seja, ele deve estimular a desmontagem das regras de produção dos discursos. O contato com o subterrâneo dos textos, com as ordens das razões e da arte retórica, pode armar os alunos de um "repertório de topoi", de uma "grelha crítica" que amplie sua intimidade com a linguagem - mesmo que essa prática coloque no centro o problema dos conteúdos programáticos, ou seja, dos limites ou margens da filosofia (Ibidem, p.220; Silva, 1986, p.15-30). O importante é produzir um "efeito de nomadização" do pensamento que evidencie o "deslocamento livre", o "movimento fluido" da palavra dissociada dos critérios transcendentes da verdade, universalidade e imutabilidade (Lebrun, 1976, p.151-2).

Mas isto pressupõe considerar a filosofia uma operação perene, uma visada ou interpretação marcada pela consciência da impossibilidade do confinamento da linguagem. Nem um "falso saber", sofístico, que tudo pode provar - no sentido da crítica socrática -, nem uma "doutrina oficial" com a "pretensão a um saber absoluto" (Ibidem, p.148-9). Mas uma escansão incansável de signos que produz "a segurança de uma dominação intelectual": "Perspectivismo significa relação estratégica na produção do conhecimento, de modo que este é sempre parcial, oblíquo. Conhecer não é explicar, elucidar, mas interpretar - atividade contínua, inacabada, voltada não sobre o significado das coisas, mas para a ação de inscrever signos. Aprender, por exemplo, implica estabelecer familiaridade prática com os signos, com o heterogêneo; aprender é constituir um espaço de encontro dos signos - 'espaço em que os pontos relevantes se retomam uns nos outros e em que a repetição se forma ao mesmo tempo em que se disfarça'. Emitir signos a serem desenvolvidos no heterogêneo é o que pode fazer toda educação (ou todo professor): apoderar-se violentamente desses signos, dominar situações, dar forma, estruturar, impor determinadas relações de força, situa aquele que se educa. Educar-se, conhecer, aprender: arte da multiplicação do sentido e da modificação da natureza dos signos que, por estabelecerem relações entre um ocultado e uma superfície, manifestam-se como sintomas. Toda educação processa-se ao nível dos sintomas para situar o intérprete na atividade de valoração" (Favaretto, 1991, p.121-8).

A aquisição de uma tópica, de uma familiaridade prática com os signos que permite ao aluno dominar situações, dar forma, estruturar, 
impor determinadas relações de força, ou seja "posicionar-se", é o resultado do abandono de um espaço codificado, marca do pensamento sedentário que fixa uma verdade ahistórica. Com isso se descarta o pressuposto de que o discurso teórico com regras de produção viciadas por uma razão soberana exista em função de um "absoluto", ignorando o sentido plural, contingente, de abertura da história. O professor deve introduzir o aluno no pluralismo e polimorfismo dos textos, muni-lo com os "meios de orientar-se no pensamento", e desenvolver-lhe uma "língua da segurança", mostrando-lhe que a complexidade da práxis impede a mobilização do sentido (Lebrun, 1976, p.151-2).

Reduzir a interpretação à postulação de uma verdade, mesmo que "provisória e reversível", é acreditar na possibilidade de "objetivação do conhecimento" (Granger, 1989, p.20). É negar o enigma da letra, e o devir da vivência, esquecendo que "a razão e o sentido não excluem a imprevisibilidade, os desvios e as angústias, uma vez que o homem está na história como quem se procura, não como quem já se encontrou" (Nascimento, 1986, p.8). É identificar, em outros termos, a filosofia, tornada normativa, à ciência. A filosofia, porém, ao contrário da ciência, "não visa organizar os fatos", trabalhando sobre modelos que simulam aquilo que deve acontecer na realidade, "mas simplesmente produzir significações" (Granger, 1989, p.14). Ela "procede da liberdade" de "escolha global de uma perspectiva sobre o significado" respeitados "certos requisitos formais", como a busca da coerência interna ou a eliminação das contradições entre os conceitos (Ibidem, p.216, 238, 248).

Além de rejeitar os fundamentos, ou meta-enunciados, o professor não deve assumir nenhum parti-pris em relação à linguagem, abrindose também ao seu engenho, à "fecundidade operatória" de seus "dispositivos experimentais" (Ibidem, p.14).

A interpretação cria mecanismos de rearticulação do texto que negam a possibilidade de um estatuto de verdade garantido por uma linguagem transparente. O poder de perspectivar "expulsa o acaso"; guiado pelo "ideal de inteligibilidade", apreende o funcionamento de uma das configurações do texto, exteriorizando "a lei que lhe é infusa" (Lebrun, 1976, p.152). Não uma "lei de essência", mas um domínio sobre a desordem que impede o "espedaçamento das significações" (Ibidem, p.152). Cada texto é um "plano de imanência", aberto, longe de ser pacífico, porém ordenado por uma "razão contingente" (Deleuze \& Guattari, 1992, p.44). O contato com essas diferentes possibilidades de interpretação, igualmente aceitáveis pelo entendimento, pode aguçar o espírito crítico do estudante, "dando-lhe uma visão muito mais rica do 
seu próprio mundo, das várias maneiras pelas quais ele pode resolver ou equacionar um problema" (Silva, 1986, p. 8).

Formar-se na escuta na leitura, é formar-se no regresso a; é perder a boa forma; furtar-se à gestalt dada; ao lugar fixo. Reexaminar os pressupostos, os subentendidos no texto e na leitura do texto é abrir-se a uma nova configuração. Nesse sentido não se pode dizer que o professor de filosofia seja um mestre, no sentido de dominar um curso, uma disciplina a ser transmitida, pois ao interrogar um texto, ele - assim como o aluno - fica exposto a essa questão; ao interrogar um tema ele é interrogado por esse tema. "Formar-se na escuta é desenvolver a escuta paciente que consiste na procura daquilo que permanece impensado mesmo quando a questão, o tema, já foi (já está) pensado" (Lyotard, 1993, p.124).

É por isso que a elaboração filosófica não tem nenhuma relação com a teoria, com um "corpus teórico", ou com o "juízo determinante" no sentido kantiano; ou seja, a experiência dessa elaboração está relacionada com a aquisição de uma "tópica" no sentido retórico e operacional, e não com o saber no sentido disciplinar. E sendo assim, conseqüentemente, a resistência dos alunos ao trabalho de escuta - como veremos - é diferente daquela que, em regra, eles opõem à transmissão de conhecimentos. O curso de filosofia "não ensina apenas aquilo que é preciso ler", mas "como se pode ler" e também "que nunca se acaba de ler", ou ainda, que "nunca se leu exatamente aquilo que se leu" (Ibidem, p.124). É nesse sentido que a leitura filosófica de um texto - pois não se trata precisamente da leitura de um "texto filosófico" - é análoga à "anamnese", no sentido psicanalítico, segundo Jean-François Lyotard (Ibidem, p.121).

Uma leitura é filosófica não porque o texto lido, como vimos, seja filosófico, a priori, haja vista que é possível ler textos considerados unanimemente da tradição filosófica - textos de Platão, Descartes ou Hegel de modo não filosófico; o que torna, enfim, uma leitura "uma leitura filosófica", e que pode ser ensinada, é esse exercício paciente de escuta do texto escrito, ou seja, a interpretação lógica dos argumentos e a marcação dos tropos, ou imagens desse texto. A aula seria, assim, a ocasião para a escuta conjunta - do aluno e do professor - de um texto no sentido da "elaboração" da linguagem e não da "aquisição de um saber"; e, neste aspecto, ela se assemelha menos à transmissão de conhecimentos e mais a uma regressão, a um recuo às interpretações passadas, mas ainda passíveis de elaboração. Se quisermos, contudo, falar de "aquisição de um saber", temos de acrescentar que se trata de um saber operacio- 
nal que, sem constituir-se em método, permite a reconstrução genealógica dos estratos semânticos atribuídos a um texto ao longo do tempo.

Essa escuta das razões contingentes de um texto - das regras ad hoc que o regem, ou seja, de seu "código" ou "ideoleto" -, pode desenvolver no aluno uma habilidade intelectual, entendida como sua capacidade de assumir uma "perspectiva" em relação a uma questão desse texto. Há, contudo, uma dificuldade a ser enfrentada pelo professor, pois a tomada de "posição" pelo aluno não é fácil, uma vez que as regras que nascem dos discursos podem não se referir a uma prática cotidiana do mundo. É importante observar, contudo, que esse desvio à linguagem - aos códigos de leitura vigentes - pode operar como uma forma de resistência à racionalidade instrumental, uma recusa à petrificação social; pois submeter-se à prosa cotidiana do mundo - o que no discurso pedagógico denomina-se partir da experiência vernacular do aluno, e, portanto, da função referencial, designativa, de uma linguagem carregada de estilemas da mass-cult - significaria abdicar aos poderes de negatividade da linguagem.

Em sala de aula ocorre, muita vez, contudo, uma redução dos "idioletos da filosofia" à "linguagem dita comum", com o objetivo de facilitar a comunicação. E essa ênfase na recepção, cujo intento é facilitar a receptividade dos alunos à disciplina, encobre a função criadora da palavra; abafa a inovação lingüística que, embaralhando os níveis de "realidade" (ou seja, a "ficção" e o mundo dito "real"; a "literatura" e a "teoria"), opõe-se ao fastio da comunicação rotineira - às expectativas pré-formadas pela experiência cotidiana. Esse foco na fruição ignora, portanto, que a filosofia sempre afirmou "a luta do pensamento contra a opinião", opôs os conceitos às idéias correntes, evitando assim o caos o abismo das significações indiferentes ou niveladas (Deleuze \& Guattari, 1992, p.60-81). Em nome de uma "conversação democrática universal" - que se diga de passagem, é uma das amarras em que patina a estratégica pedagógica - não se pode, por exemplo, sacrificar a "auto-referência dos textos" (Ibidem, p.80). Diante do destampatório dos discursos, a saída é a recusa secreta que ativa a reflexão. O professor deve introduzir seu aluno na experiência inaugural do estranhamento, num desenraizamento que o fisgue do falatório (do repetir e repassar adiante - mais uma vez - a mesma fala), ativando-lhe a curiosidade pelas possibilidades e ambigüidades dos discursos. Colocando o universo da comunicação generalizada entre parênteses, o professor impedirá, assim, a separação e especialização do estético, resgatando a linguagem da opinião corrente, em particular, da doxa mass-mediática. 
Além disso, o texto que se refere tão-somente "a algo no mundo", como quer Jürgen Habermas (1990, p.131-47), ignora que há um "único acontecer textual universal": só uma crítica que, sem desconsiderar a função referencial da linguagem e a rede de relações lógicas que constroem os argumentos, também se detiver nas figuras formadoras de estilo, tratando neste sentido o texto também como texto literário, poderá apreender a realidade da linguagem filosófica. Só assim tornaremos interligados o uso da linguagem e os deslocamentos em sua estrutura, a invenção de conceitos e as irrupções da criação literária. E mais: estendendo a experiência estética, que reconhece à palavra o poder de "abrir mundo" - na expressão de Jacques Derrida, no rastro de Martin Heidegger - talvez não precisemos aceitar com Ítalo Calvino, ou mesmo com os "pós-estruturalistas" franceses, que "o verdadeiro sujeito primeiro da escritura nos aparece cada vez mais distante, mais diluído, mais difuso: que talvez se trate de um "eu fantasma, de um lugar vazio, de uma ausência" (Ibidem, p.247); mas devemos ao menos, admitir que esse sujeito da escritura é na verdade um modo de produção do discurso não um "eu natural" ou uma subjetividade empírica - mas um "agente de enunciação", uma "atitude do pensamento" (Deleuze \& Guattari, 1992, p.60-81).

Enfim, o professor de um curso de filosofia, no ensino médio ou na universidade, deve mostrar que a linguagem, a cada texto, se autoapresenta com sua impotência em demarcar um conteúdo transcendente de verdade, sem recair, contudo, num alarde cético que afirmando a gratuidade das significações desdenha a educação da inteligibilidade. O aluno, por seu lado, deve apreender que, no âmbito da racionalidade, cada filosofia possui "seus próprios critérios de validade e de objetividade, solidários com o restante de seus enunciados e em harmonia com a estrutura de todo o edifício" (Pereira, 1975, p.14); e que, portanto, embora não exista uma "fundamentação absoluta" ou uma "legitimação definitiva" é "possível encontrar respostas razoáveis e coerentes" aos diferentes problemas (Ibidem, p.15).

O professor, que introduz seu aluno à interpretação filosófica dos textos, deve evidenciar-lhe a impossibilidade de uma comunicação transparente fundada no senso comum, que, imobilizando o sentido das palavras concilie os interlocutores. E deve mostrar também que uma razão crítica que denuncia o repositório de estereótipos, embora persuasiva, não se refere, na maioria dos casos, à dita "realidade", ou aos fatos imediatamente vividos; ou ainda: que o texto é composto de abstrações que, mesmo quando submetidas às medidas da lógica - ou, em sua fal- 
ta, dos "juramentos" como quer Roland Barthes (1984, p.148; 1998, p.123) -, são criações literárias, "ficcionais": incapazes de "autenticar", sem mediações, o real, razão de seu infortúnio, mas também, de sua "voluptuosidade".

O professor, este filósofo funcionário que, sem ceder ao ceticismo, recusa os dogmas e o relativismo, considera a filosofia um "jogo de construção", um operador de discursos ao mesmo tempo formal e simbólico, que põe em crise os lugares da "linguagem de conversação" (Granger, 1989, p.255; Barthes, 1998, p.123-33). Em sala de aula, o professor experimenta o rigor do texto, rendendo-se às suas figuras.

\section{O espaço público}

Considerar, assim, o curso de filosofia uma arte da escuta da articulação lógica e da fulguração poética dos discursos, é vinculá-la à Bildung, uma vez que esse curso visa desenvolver no aluno "a consciência ou faculdade de pensar em seu sentido mais profundo", como dizia Theodor Adorno (1995, p.151), não apenas ensinando-lhe as regras da lógica formal, mas também estimulando "sua capacidade de fazer experiências intelectuais", portanto discursivas; pois como vimos, a "escuta" nega a instrumentalização da linguagem: "Suspende-a", diz Jean-François Lyotard (1993, p.121): "Se um dos principais critérios da realidade (competitiva) e do realismo (neoliberal) é ganhar tempo", o curso filosófico não está conforme a realidade atual.

Épor isso que os alunos, em regra, não estão dispostos à paciência, à "anamnese", ao recomeço, a essa espécie de regresso à infância do pensamento, exigida pela atitude filosófica. Lyotard, por exemplo, caracteriza a leitura filosófica, metonímia da atividade filosófica em geral, como sendo um "exercício de paciência". "E nessa bela expressão de Lyotard - como assinala Jeanne Marie Gagnebin (1999, p.87) - intervém uma outra dimensão do exercício da filosofia (e que talvez seja um dos grandes ensinamentos dos cursos de filosofia, bem como as resistências que eles, muitas vezes, encontram nos alunos): sua demora, suas hesitações, sua perda de tempo e seu tempo perdido, sua paciência, enfim, que se opõe à temporalidade da produção e do consumo capitalistas, isto é à voracidade e à pressa" (Ibidem, p.88). (parênteses nossos). A "leitura filosófica" pressupõe, em outras palavras, a espera e a lentidão num mundo regido pela mídia eletrônica e pela informática que, 
possibilitando a informação e os intercâmbios em "tempo real", criam uma "sensação de simultaneidade e imediatez"; em suma, pelo próprio capitalismo financeiro, que põe em xeque toda visão de longo prazo, em favor da circulação acelerada de capitais em escala global (Virilio, 1993, p. 40; Lipovetsky, 2004, p.87). A resistência que a filosofia suscita - e que deve ser preservada - por vezes parece, assim, insuperável, pois os alunos falam o idioma de um mundo que fala (e não se trata aqui de um mundo transcendental, no sentido do "mundo da vida" habermasiano (lebenswelt), mas de um mundo colonizado pela esfera da técnica e da ciência, ou seja, pela operation, pelo procedimento eficaz): "Gozo", "narcisismo", "competitividade", "sucesso", "performance", "realização" - retomando Lyotard, via Gagnebin (1999, p.88).

A maior dificuldade do professor de filosofia é desse modo, exigir do aluno a paciência necessária, ou melhor, "mostrar-lhe que ele deve suportar não progredir de forma calculável, aparente" - que ele deve, enfim, "começar sempre" - "o que nega os valores atuais do prospectivismo, do desenvolvimento mensurável, da velocidade ou, como dizíamos, do gozo imediato" (Lyotard, 1993, p.122). Pois se sabe, como enfatiza Lyotard, que "o mundo real fala sob a regra da troca econômica, generalizada sob todos os aspectos da vida, incluindo as afeições e os prazeres" (Ibidem, p.122); e esse "idioma" do mundo compartilhado é de todo indiferente, senão antagônico, àqueles do curso filosófico: ou, ainda, é sua própria negação. ${ }^{3}$

No curso de filosofia, o tempo da troca e da mercadoria deve ficar suspenso, ou mesmo ser abolido. Não é preciso, numa aula de filosofia, que o aluno entenda depressa o texto ou que apreenda rapidamente seus conceitos, porque isso implicaria ser por eles apreendido, ficando deles refém. É necessário abordar lentamente um dado problema, para que esse pouco a pouco adquira uma configuração, ainda que provisória. Roland Barthes (2003a), a propósito dessa intenção, sintomática de nosso tempo, de agarrar-se a um conceito para pacificar prontamente o pensamento, diz que as pessoas que entendem depressa lhe dão medo. Nessa direção pode-se ainda dizer que essa adesão incontinenti ao con-

3 Nesse sentido, seria preciso pensar - mas apenas indico, aqui, essa necessidade - a relação entre o ensino da filosofia e a Universidade enquanto espaço institucional. Até mesmo porque é possível estabelecer um paralelo entre a filosofia e a universidade, pois, como a filosofia, a universidade deveria se distinguir - como mostra Jacques Derrida (2003, p.21) - à revelia da tendência atual, de todas as instituições de pesquisa que estão a serviço de finalidades e de interesses estritamente econômicos de todo tipo, etc. 
ceito, para instrumentalizá-lo, é uma forma de reafirmação da realidade existente, ou de reforço do status quo, pois no mundo atual, só "uma técnica que diminua a velocidade tem algo de progressista" (Barthes, 2003a, p.79; 2003b, p.35).

Nesse curso, o aluno, além da "arte (ou techné) da demora", deve aprender a "des-tecer" o discurso em busca de suas inflexões, sintáticas e semânticas. Deve-se somar ao ralanti, ao "adiamento" da "configuração final", a busca de matizes ou cambiâncias, aquilo que Barthes (2003a, p.27), inspirando-se na palavra grega diaphora ("diferença" ou "desacordo") chama de nuance - "uma mercadoria cada vez mais rara, senão um verdadeiro luxo no presente". O aluno deve perceber que cada texto é "um espaço totalmente e como que exaustivamente matizado"; cada texto é "furta-cor": ele muda sutilmente de aspecto, talvez de sentido, ou de configuração, segundo a inclinação do olhar do leitor (Ibidem, p.29). Essa busca da "nuance", que aqui se propõe, não significa - entenda-se bem - uma reivindicação de sofisticação intelectual, no sentido de uma estilização do pensamento, mas apenas o desapego indispensável por parte do aluno, do sentido "pré-fixado", "dogmático" da linguagem. Na aula de filosofia, portanto, a diaphora deve produzir uma epokhé - a "suspensão provisória" das ordens, leis, cominações, arrogâncias, terrorismos, intimações, exigências da língua. Não significa, contudo, que esse exercício de produzir nuances deva se eternizar, pois é necessário que o aluno - que não atribui aos conceitos, de imediato, uma "consistência de verdade" - constitua, a uma dada altura da leitura, um "espaço de linguagem" (uma "língua da segurança"), em cujo interior se situe; para que possa então, denunciar a "arrogância da língua" que é tomada como natural, "anônima" - ou dogmática. ${ }^{4}$

O curso de filosofia deve abrir um espaço também para o silêncio. É claro que é na aula que se deve dizer tudo, mas é preciso também postular que nela seja garantida a possibilidade de calar-se. Esse silêncio, condição necessária à reflexão - pois é preciso parar para pensar não é um "silêncio da boca", mas uma recusa em endossar a fala que é aceita na sua superfície, na sua contingência; - à fala, enfim, dita sistemática, dogmática (Ibidem, p.49-60). Deve-se buscar uma forma de silêncio que resistindo ao falatório ou tagarelice, desmonte as falas en-

4 Nesta constatação da necessidade de se interromper, ainda que temporariamente, o exercício de "esquiva", de "deriva" da língua, para que se efetue uma crítica dos "lugares de conversação", nos distanciamos de Roland Barthes. 
quanto discursos constituídos. O silêncio denuncia essa pulsão à fala, "o cansaço da linguagem", seu "trabalho forçado" no cotidiano, pois instaura uma "pausa legítima - como diz Maurice Blanchot - que permite a alternância nas conversações; uma escuta benevolente, inteligente, ou ainda "a bela espera com a qual dois interlocutores, de um extremo ao outro, medem seu direito a comunicar-se" (Ibidem, p.313). Não significa, evidentemente, que é desejável que o aluno se feche num silêncio permanente, que, para contrariar a fala dogmática acabe por se converter, ele próprio, em silêncio também dogmático; pois é preciso, a certa altura, falar, para que o próprio silêncio não perca a significação. É necessário produzir em sala de aula, em outros termos, um jogo de fala e silêncio que não seja sistemático; uma efetuação de fala que tenda a neutralizar o silêncio, e uma operação de silêncio que coloque em suspeição a fala corrente; e pôr em questão a "esfera da doxa" significa colocar entre parênteses a língua, entendida como "aquilo por quê, querendo ou não, somos falados" (Ibidem, p.91). Entenda-se a língua, aqui, não somente no sentido de sintaxe (ou de gramática), ou de semântica (porque relativa aos significado das palavras), mas no sentido de "lugares comuns", ainda que ilustrados, que, funcionando como leis coercitivas nos obrigam a falá-los, ou - como se dizia nos tempos do "estruturalismo lingüístico" -, que sejamos por eles falados; é por isso que até o silêncio, que possibilita a análise do discurso, é também, nesse particular, uma reação ao "fascismo da língua", na expressão de Roland Barthes (1996, p.14).

Se a sala de aula for considerada uma "ágora residual", marcada pela phiíia ou tolerância, nela, não terá lugar, a repetição ou repisamento de falas; afinal, como dizia Barthes (2003a, p.72), "a delicadeza horroriza-se, melindra-se com a redundância". É também nesse sentido que a aula de filosofia é crítica, pois nela evidenciam-se os limites sociais, políticos, ideológicos das falas, ou dos lugares de enunciação; dito de outra maneira: o curso de filosofia precisa "brigar" com a língua, o que significa dizer que a filosofia, enquanto anamnese ou "leitura filosófica" deve desfazer a aparência de "assertividade natural" da língua, revelando sua dimensão de construto ou convenção.

O professor deve ser cuidadoso, contudo, em relação ao "remédio pedagógico" a ser adotado para vencer a resistência aos cursos de filosofia - que decorre, em grande medida como víamos, do fato deles virem de encontro às demandas pragmáticas do presente. Não se deve retirar da filosofia o efeito de estranhamento que a caracteriza desde sua origem, mas, ao contrário, intensificá-lo. A "saída pedagógica" não é 
assim a "sedução do aluno", com o pronto atendimento de suas expectativas, mediante estratégias demagógicas que produzem a espetacularização da filosofia; ou seja, sua redução ao entretenimento, à distração: a uma collage de curiosidades palatáveis ao modo dos produtos da mass-cult. Destaque-se, todavia, que uma das táticas mais corriqueiras, visando a legitimação do curso de filosofia, e, por conseqüência, da própria atividade do professor, tem sido justamente o "afago narcisista" do aluno. A apologia incondicional de tudo o que é dito em sala, muito diferente da philía, enquanto acolhimento da fala do outro, produz uma espécie de discurso encomiástico, ou ditirâmbico, uma forma de assassinato pelo "cumprimento excessivo" do trabalho do pensamento do aluno; pois como dizia Joseph de Maistre: "Toda apologia - inseparável, nos dias que correm, da ideologia do desempenho e da competitividade - deveria ser considerada um assassinato por entusiasmo" (Ibidem, p.121). (travessões nossos).

Nesse sentido, "o trabalho de anamnese e a elaboração em ato numa aula, quer seja alegre ou severa, não deve nada ao aliciamento" (Lyotard, 1993, p.123). Evitá-lo não significa, porém, aderir ao seu contrário, ao conflito, à disputa com os alunos, numa espécie de agonística, que afasta as partes. É preciso salientar, também, que o único espaço, que de algum modo ainda se assemelha à antiga "ágora grega", é o espaço da sala de aula; e que, portanto, é aí que o ágon - o momento crítico, de decisão, em que se vive angústia, ânsia, medo, inquietação pode aflorar; a sala de aula é em suma o único lugar, em tempos de suposto "pensamento único", em que ainda se pode amar as discussões. Se a aula, em suma, "não tem o poder de mudar a vida, é, sem dúvida, ainda, uma de suas faces mais intensas: ela é o lugar - e nesse aspecto se aproxima da 'obra de arte' - onde o sentido ainda insiste em presentificar-se" (Favaretto, 2004, p.270).

$\mathrm{Na}$ aula de filosofia pode ocorrer, assim, uma recusa à redução, sempre violenta, da fala do outro a um discurso estereotipado, "paradigmatizável" (ou sem nuances), numa "fuga elegante e discreta diante de todo dogmatismo" (Barthes, 2003a, p.80). Esse exercício de suspensão dos julgamentos, que evita o enquadramento das falas, pode produzir até mesmo, algum tipo de philía - como sugeríamos - alguma forma de tolerância ou urbanidade, ou ainda de delicadeza ou brandura; de disposições ou sentimentos, enfim, cada vez mais raros em outros contextos; afinal o cuidado com a língua incentiva a tolerância, na medida em que impede protocolar as falas, arquivar os temas, fichar os sujeitos dos enunciados, atribuindo-lhes um predicado, um adjetivo definitivo. Essa 
atenção paciente aos matizes das falas pode, assim, evitar a agressão pelo adjetivo, ou seja, o julgamento incontinenti da fala do outro, ou a atribuição de rubricas ao autor de um texto. Predicar de imediato é, afinal de contas, asseverar, encerrar a fala, enclausurar o pensamento, ou seja, esterilizar a língua, ao invés de saboreá-la, de "diferi-la", de "derivá-la", de "lustrá-la", como quer Roland Barthes (Ibidem). Essa busca da nuance, tanto nos significados das palavras quanto nas inflexões dos argumentos, não significa - vale frisar - algum tipo de impotência ou passividade, mas, ao contrário, implica atividade, se aceitarmos que o aguçamento da sensibilidade para o discurso é condição necessária da "ação no mundo". ${ }^{5}$

A sala de aula, contudo, seria mesmo uma espécie de ágora residual? E o professor de filosofia teria ainda, efetivamente, alguma função a desempenhar no espaço público? O Iluminismo, e em seu interior o pensamento kantiano, colocaram - como se sabe - a escola no centro do interesse popular e prático da razão. A filosofia, indissociável para Kant (1985, p.100) da idéia de "República", teria a função de contribuir com a emancipação do homem, ou seja, de estimular o homem a fazer uso de seu entendimento, a "servir-se, em suma, de si mesmo", "sem a direção de outrem". Esse lema da Auflklärung, que orientou a perspectiva moderna em educação teria, entretanto, sentido ainda hoje, em tempos ditos "pós-modernos"? "Será, em outros termos, que o mundo ainda pede à filosofia que de algum modo legisle prática e politicamente"? Ou ainda: "Será que alguém ainda pede algo, o que quer que seja da filosofia?" (Ribeiro, 2003, p.123-49).

No intento de devolver à filosofia sua dimensão republicana, Jacques Derrida (2003, p.47) afirma que "a aula de filosofia, sobretudo no interior da Universidade, deve ser o lugar em que nada está livre de questionamento; nem mesmo a idéia tradicional de crítica, como crítica teórica, nem mesmo ainda a autoridade da forma 'questão', do pensamento como 'questionamento'. Nela, deveria vigorar: o direito de princípio de dizer tudo, ainda que a título de ficção e de experimentação do saber, e o direito de dizê-lo publicamente, ou seja, oralmente ou, por escrito, mediante publicações'. É no conceito de espaço público, afinal, que temos o elo de filiação da vida contemporânea à era das luzes" (Lyotard, 1993, p.124).

5 Conferir a propósito da relação, aqui sugerida, entre a "palavra viva" e a "ação vivida", ou ainda, entre "vita activa" e "vita contemplativa" a reflexão sobre "democracia" de Hannah Arendt (1981, p.302-7) 
Para que a filosofia preserve esse caráter republicano, ou ainda, para que ela mantenha algum vínculo com a idéia de emancipação, não pode ficar confinada aos cursos de graduação em filosofia, ou a algumas escolas particulares, ditas progressistas, de ensino médio. Não basta tampouco que ela seja matéria meramente opcional nas escolas das redes, municipal ou estadual. Deve, ao contrário, estender o seu campo de atuação, sem que isso implique a perda de sua especificidade; e deve se voltar - como observa Jean-Francois Lyotard (1993, p.124) - não apenas aos jovens, mas também aos adultos; até mesmo porque "o pensamento talvez tenha mais infância - ou seja, esteja mais disponível para efetuar uma anamnese, na vida adulta", e mesmo fora dos cursos regulares, do que em seu interior.

A defesa da difusão da filosofia não é, contudo, antagônica à identificação, comum em certo meio universitário, entre o filósofo e o historiador da filosofia, entendido como aquele que faz de sua atividade um "trabalho de luto inconsciente" nunca terminado? (Ribeiro, 2003, p.133). Não será que debatemos - na pergunta de Renato Janine Ribeiro - mais autores, ou textos, do que idéias? Não haveria, assim, no âmbito da filosofia enquanto disciplina, "idéias sem nomes próprios?" (Ibidem). Não é possível produzir, em outros termos, argumentos consistentes, plausíveis sem que se recorra a um autor da tradição que lhes dê legitimidade? Não estaríamos reféns de um expediente retórico sempre invocado, o "argumento da autoridade"? Tomar o "nome próprio" por "proprietário de idéias" não implica, em suma, silenciar o "nome comum", o "sujeito ordinário" de enunciados? (Ibidem). E esse procedimento não implicaria um enfraquecimento da própria discussão, seu confinamento a configurações já dadas e a interlocutores cuja posição já é a priori conhecida, e, por conseguinte, uma atrofia do espaço público?

Durante o processo de implantação dos cursos de filosofia no Brasil, considerou-se num exercício de profissionalismo e humildade, que não haveria mais filosofia a fazer, uma vez que os "tempos da filosofia" já teriam passado; de tal modo que restaria aos alunos, sobretudo aos mais diligentes, a tarefa briosa - simultaneamente modesta e desafiadora de estudar com rigor uma filosofia já dicionarizada. Só seria possível fazer "história da filosofia", cabendo ao "intérprete", tanto ao professor como ao aluno, o papel de um "sacerdote", e à filosofia, a função de uma "religião já completada" (Ibidem, p.136). Restaria ao "historiador", portanto, interpretar, e se possível de modo original, essas "escrituras", entendidas como evangelho, como um conjunto de preceitos pelos quais se regula uma seita; e, não, como propúnhamos, no início - no sentido 
de Roland Barthes ou Jean-François Lyotard -, como uma escrita plena de pulsão que trapaceia com as normas da língua.

A "audácia da filosofia" acabou, assim, restrita à interpretação supostamente "original" de um termo ou de um argumento de um texto considerado clássico da "História da Filosofia". Não se pode, contudo, atenuar a importância que esse método de interpretação de textos, herdeiro da missão francesa iniciada em 1934, e em particular do estruturalismo de Martial Guérroult e Victor Goldschmidt, teve no processo de formação da filosofia no país. Essa fase do serviço militar obrigatório foi indispensável, como se sabe, na medida em que priorizou o contato direto com os textos originais, em detrimento das leituras impressionistas ou amadorísticas que reinavam entre nós.

Esses benefícios, contudo, não podem encobrir os problemas que esse método nos legou: ${ }^{6}$ o primeiro, é que o "filósofo" (o "profissional da filosofia") se especializou de tal modo em história da filosofia que acabou por dissociá-la das demais ciências humanas, como a sociologia, a política e a arte; a segunda conseqüência, é que esse método, voltado para a análise interna do texto, colocou entre parênteses a história, seja o contexto em que o texto foi produzido; seja o contexto de sua recepção; em terceiro lugar, essa identificação do intérprete a do perito fez do autor do texto (do "filósofo" estudado) refém de seu leitor. O "intérprete", convertido em expert, foi tomado, muita vez, como representante oficial do autor, o que implicou um encolhimento da ágora, haja vista que toda fala que se apresenta como oracular impede a polifonia - a constituição de uma companhia que decorre do "estar-junto" no espaço público; o quarto problema, por fim, resultante dos anteriores, é a dificuldade dos "filósofos", senão da própria filosofia, assim instituída, de pensar o presente.

Em virtude dessa especialização da filosofia, estaria havendo um "déficit" de pensamento, segundo Renato Janine Ribeiro: "está se pensando, entre nós, de menos" (Ibidem, p.148). ${ }^{7}$ Estaria havendo uma "timidez da filosofia", decorrente da história de seu ensino no país, que a impediria de pensar o presente, de modo lógico e consistente, e sem a

6 Limito-me a reconstituir, nesse parágrafo, com adendos, alguns dos argumentos de Renato Janine Ribeiro (2003, p.136-49).

7 Reforçando essa posição acrescento dois exemplos, colhidos dos campos da política e da teoria da arte. É necessário repensar o sentido que conceitos centrais da filosofia política moderna, como "Estado", "nação", "soberania", "representação" ou "ideologia", adquiriram em tempos "neoliberais"; bem como, o sentido que a "arte" vem assumindo no interior da "sociedade do espetácu- 
necessidade de invocar, a cada passo da argumentação, a auctoritas de um texto da tradição. Seria preciso, assim, na tentativa de constituir uma "língua comum de segurança" que nos permitisse falar "coletivamente" sobre o presente, "laicizar" a filosofia, o que não significa renunciar ao esprit de sérieux - que não pode ser identificado à tristeza ou à melancolia - exigido pela leitura filosófica. Não é, afinal, da arrogância que o conceito retira o seu poder de persuasão; basta notar que é na fala prescritiva, blockbuster, de tom empertigado, que o sujeito da enunciação encobre, muita vez, a tibieza de seus argumentos. É possível enfim, "rir", não da filosofia, mas com a filosofia, como mostra Nietzsche em "A Gaia Ciência": é necessário "zombar de todo pensador que não zombou de si mesmo" (Ibidem, p.144). Se de início reivindicávamos o direito da filosofia à figura - que não deve ser contraposta ao conceito -, agora reclamamos seu direito ao riso (não ao riso castrador, mas ao sorriso indulgente), que não pode ser contraposto, à "razão contingente". Não é possível, por exemplo, continuar atribuindo ao sistema, enquanto modalidade discursiva da filosofia, um poder de punch argumentativo - uma dignitas e gravitas - que a ensaística, levianamente associada à leviandade, enquanto gênero menor, porque contaminado pela literatura, não possuiria.

"O ensaio apenas desenvolve os pensamentos de um modo diferente da lógica discursiva", nas palavras de Theodor Adorno (1986, p.176): ele coordena os elementos, ao invés de subordiná-los; e, portanto, só a essência do seu conteúdo, e não o seu 'modo de exposição' é que é comensurável aos critérios lógicos". "Fazer o luto do ideal de sistema não significa, portanto, o triunfo da incoerência, da arbitrariedade e do relativismo; significa muito mais pensar até seu fundo abissal, esse co-pertencer originário entre pensamento filosófico e linguagem - em última instância, entre razão e linguagem" (Gagnebin, 1999, p.84). É preciso lembrar, por exemplo, que os próprios conceitos filosóficos, que não devem ser identificados à abstração dos universais, são elásticos, variáveis, pois se submetem à força de extravio dos significados, embora se mantenham imantados pelo traço distintivo de cada texto; eles passam uns nos outros, se co-determinam, sofrem mutações conceituais. O discurso filosófico abriga, além disso, personagens conceituais, heterônimos filosóficos, como Sócrates, Don Juan ou Zaratustra; ele utiliza "figu-

lo", haja vista que ela se deslocou - utilizando antiga dicotomia - da "superestrutura" a "infraestrutura", uma vez que se converteu, em vários países - como a indústria cultural -, em "força produtiva", em "fonte de riqueza", tornando-se assim uma questão de política econômica dos governos. Esses exemplos, entre tantos possíveis, visam apenas corroborar a idéia de que há uma "falta" da filosofia em pensar o presente. 
ras estéticas" ou "formações simbólicas"; exprime-se por imagens, metáforas ou neologismos - como em Jean-François Lyotard, Gilles Deleuze ou Gaston Bachelard -, que impedem a redução dos conceitos às forças lógicas (Granger, 1989, p.20). Até mesmo Martin Heidegger, um autor metafísico que exerceu uma grande influência sobre os franceses, atribui à poesia a função de instauração do ser pela palavra, o poder de dizer a origem. Seria então a "poiesis" no sentido de criação de linguagem, de nomeação das coisas, que ataria a literatura à filosofia.

O professor de filosofia, em suma, deveria conciliar a habilidade técnica na leitura filosófica à difusão da disciplina a um público mais amplo; o que implica reclamar, numa reação à dita "filosofia profissional", o direito da filosofia à imagem e a experimentação da língua. É importante essa observação, porque a mobilização do sistema como o gênero por excelência da filosofia dita profissional pode implicar, no debate de uma dada questão, a exclusão do "leigo culto", oriundo de outras áreas, e, conseqüentemente - também por esse motivo - o esvaziamento da ágora; e por que deveríamos, afinal de contas, descartar esse "leitor nômade, que freqüenta gêneros diversos", que lê "mediante fragmentos, que dissolve a unidade das obras em aforismas, que é, em suma, inconscientemente nietzscheano ou pós-moderno?" (Ribeiro, 2003, p.141); e por que supor, de modo análogo, que a "razoabilidade" se encontre apenas no texto que se apresenta como sendo de uma coerência sem fissuras, ou seja, destituído de pontos cegos?

\section{0 acontecimento}

A aula de filosofia é um ato performativo singular que pode engendrar algo análogo a uma "obra assinada", ou a um "acontecimento" entendido como algo inesperado que advém num lugar institucional determinado. Por isso, "no cibermundo, no mundo da Internet, do e-mail e do telefone celular, o trabalho do professor - como mostra Jacques Derrida (2003, p.60) - vai a contrapelo do teletrabalho, da virtualização do trabalho, pois o ensino da filosofia, em sala de aula, é indissociável da experiência do lugar, de ter lugar, do 'acontecimento' e da 'obra'; do que 'acontece no acontecimento'" (Ibidem, p. 60). ${ }^{8}$ Pode-se pensar, as-

8 É claro que essa "escuta" do que "acontece no acontecimento", só é possível se a atividade do professor não for rotineira, massificada, sub-remunerada etc. Deixamos, contudo, por ora, essa importante questão de lado, destacando apenas - no rastro de Derrida - que a singularidade de cada aula reside na percepção do que nela - na aula enquanto discurso - irrompe de modo intempestivo. 
sim, a aula enquanto "acontecimento" - e também aqui refiro-me tanto ao ensino médio quanto ao ensino superior - em dois sentidos: $\left.1^{\circ}\right) 0$ acontecimento em sentido fraco: "o professor pode produzir e determinar um acontecimento com um ato performativo garantido, por convenções; nesse caso, não se pode dizer que nada aconteça, mas sim que o que chega a acontecer permanece controlável e programável; não há nesse caso um horizonte de antecipação ou de pré-compreensão: mas, um horizonte simplesmente (...). Isso é da ordem do poder, do "posso", do "estou habilitado a" (I may, I can). Nenhuma surpresa, portanto, ocorre aqui; nada de acontecimento no sentido forte" (Ibidem, p.77). $2^{\circ}$ ) $O$ acontecimento em sentido forte: por outro lado, se irromper na aula "algo" como o deslocamento do sentido de um termo; um silêncio que opere como uma efetuação de sentido; uma nova configuração argumentativa a uma antiga questão da tradição; ou, sobretudo, uma relação inesperada entre a tópica de um texto (seu ideoleto) e os lugares comuns do discurso (o mundo dos clichês) estaremos diante de uma "eventualidade singular", de algo que "acontece no acontecimento"; estaremos face - na língua de Derrida (2003, p. 78) - ao "chegante", ou ao "isso", inclusive no sentido psicanalítico de pulsão, de inconsciente, do outro do sentido; do impensado, que rompe com o horizonte do provável, interrompendo toda organização performativa, toda convenção ou todo contexto dominável por um convencionalismo.

O professor deve estar, assim, atento ao "isso", que eventualmente pode advir na sala de aula; ao "im-provável", entendido como uma operação discursiva que ultrapassa o performativo, evidenciando, num rompante, a independência incondicional do pensamento. Dizer, em outros termos, que a aula, em sentido forte, é o que "acontece no acontecimento" significa que o que está em jogo no curso de filosofia, é a possibilidade de ocorrência do "trabalho do pensamento"; ou seja, de se produzir uma "língua menor" no interior de uma "língua maior", rompendo-se, assim, com a "gorda saúde dominante", na expressão de Nietzsche. Significa também, que a aula enquanto "o que acontece no acontecimento", pode operar, como dizíamos, como uma forma de resistência ao ritmo do calendário ou do cronograma - ao ritmo do cotidiano: da vida do pensamento sedentário. Na aula a "idiorritmia" (do grego ídios: próprio, particular; e rhythmós, ritmo) pode opor-se, em outros termos, ao ritmo metronômico, do relógio, do regimento, da troca. Nela, talvez, se possa viver novamente o rhythmós como rhêin, no sentido etimológico do termo: como algo que escorre, que flui; como um ritmo flexível, disponível, móvel, modificável, como uma forma passageira do 
pensamento que, ainda que configurável num tópos de razoabilidade, se furta a todo esquema (schêma) - ou seja, às formas fixas, realizadas, objetivadas (Barthes, 2003b, p.15; 68).

A cada aula, em síntese, há a possibilidade de se elaborar, a partir da "leitura filosófica" de um texto, uma língua menor, um código ad hoc, que estruturando a discussão permita o "trabalho do pensamento". A posse desse "repertório de topói", que não se deve cristalizar em doutrina, permite ao aluno operar a suspensão dos lugares de conversação. E é a essa relação entre os discursos; ao "isso" que advém de súbito em sala de aula, ou ainda, à irrupção dos topói, que se subtraindo aos schemas possibilita a desconstrução dos clichês, que deve se ater o professor.

O "trabalho do pensamento", assim concebido, pode romper com a inibição da filosofia, resultado de seu período de formação, ao pensar de modo lógico, mas também de maneira crítica, álacre e lúdica, questões relevantes do presente. Quebrando a barreira entre os gêneros dos discursos, entre as diferentes disciplinas, e entre os diversos interlocutores, esse "trabalho do pensamento" pode contribuir para que a filosofia adquira definitivamente entre nós, sua madureza. O ensino de filosofia, não apenas no interior dos departamentos de filosofia, mas também nos demais cursos universitários, no ensino médio, e mesmo fora deles, tem, portanto, a tarefa de engendrar uma "língua da segurança" que nos permita falar "coletivamente" do presente; que nos habilite, enfim, a produzir um diálogo intenso, entre múltiplos sujeitos de enunciação; o que significa, em outros termos, que a filosofia, ou antes, que a "leitura filosófica" pode - sem prejuízo da historiografia da filosofia - contribuir para suprir nosso déficit primário de análise do presente. O ensino de filosofia é fundamental, portanto, nessa tarefa de constituição de um espaço publico, pois "nos demais domínios da vida, ou mesmo no interior das demais disciplinas, pouca importância concedemos àquilo que nos é comum" (Ribeiro, 2003, p.148). A leitura filosófica pode contribuir, em outros termos, para que "as idéias que migram soltas", ou que se encontram enclausuradas, se evidenciem, em novas configurações lógicas, ou seja, em novos discursos de razoabilidade (Ibidem, p.147).

Essa exigência de se fazer com que a língua rompa com as formas de "axiomatização do capital" - que apagam o seu caráter de construto, de produto da cultura - não é propriamente, como salientávamos, uma exigência pedagógica, uma vez que não constitui, nenhum método de ensino, nenhuma ciência, nenhum saber transmissível (Deleuze \& Guattari, 1992, p.9-21). Essa abertura do professor à indeterminação, ou ao incomensurável da experiência pressupõe, além disso, um amplo do- 
mínio de referências culturais, ou seja, de um repertório de textos da história das ciências, das artes, ou da política, bem como uma habilidade em relacioná-los com os lugares de conversação. Como essa postura "didática" não constitui propriamente um método, é preciso contar com o autodidatismo do professor, com sua experiência adquirida em lidar com o imponderável - com as formas inesperadas com que os "estereótipos" e os "ideoletos" se relacionam no interior de um curso. O professor deve desenvolver, assim, uma espécie de "atenção flutuante", uma visão intersticial, capaz de captar os desvãos - o breve clarão - na aula de cada dia. Nisso o curso se aproxima da escrita, pois do mesmo modo que "se escreve antes de se saber o que há a dizer" - como diz JeanFrançois Lyotard (1993, p.120) - o professor inicia uma aula sem saber o que nela - ou se "algo" nela - ocorrerá.

FABBRINI, R. N. The teaching of philosophy: the reading, the interpretation and the event. Trans/Form/Ação, (São Paulo), v.28(1), 2005, p.7-27.

- ABSTRACT: The Philosophy Course must develop in the student a technical ability for the interpretation of different discursive modalities - analogue to the "suspended atention", in the psychoanalytical sense - which will provide the student with the experience of "intelectual mastering", of ownership, however provisional, of a "language of safety", which holds in "suspension" the "places of conversation". By breaking the barrier between genres of discourses, between different subjects and between the various interlocutors, the course of philosophy - whether it is taught in the university or in high school or even outside the regular courses - may, in this way, stimulate the production of an intense, laicized dialogue among multiple subjects of enunciaton, contributing for the constitution of the "public space". Only in this way can philosophy definitely conquer its maturity among us.

- KEYWORDS: Philosophy; education; teaching; Lyotard; Barthes; Derrida.

\section{Referências bibliográficas}

ADORNO, T. W. Educação e emancipação. São Paulo: Paz e Terra, 1995.

O ensaio como forma. In: COHN, G. Theodor W. Adorno. São Paulo: Ática, 1986, p.167-87.

ARENDT, H. A condição humana. São Paulo: Forense Universitária, 1981. 
BARTHES, R. A câmara clara. 2.ed. Rio de Janeiro: Nova Fronteira, 1984. . A aula. São Paulo: Cultrix, 1996. - O rumor da língua. São Paulo: Brasiliense, 1998. . O neutro. São Paulo: Martins Fontes, 2003a.

Como viver junto: simulação romanesca de alguns espaços cotidianos. São Paulo: Martins Fontes, 2003b.

DELEUZE, G., GUATTARI, F. O que é filosofia? Rio de Janeiro: Editora 34, 1992. DERRIDA, J. A Universidade sem condição. São Paulo: Estação Liberdade, 2003.

FABBRINI, R. N. O ensino de filosofia no $2^{\circ}$. grau: uma "língua da segurança". In MUCHAIL, S. T. Filosofia e seu ensino. São Paulo: Educ, 1995. p. 77-85.

FAVARETTO, C. F. Pós-Moderno na educação? Revista da Faculdade de EducaÇão da Universidade de São Paulo, v. 17, p. 121-28, 1991.

Notas sobre o ensino de filosofia. In: MUCHAIL, S. T. Filosofia e seu ensino. São Paulo: Educ, 1995, p.77-85.

Moderno, 'pós-moderno, contemporâneo na educação e na arte. São Paulo, 2004. Tese de Livre-Docência em Metodologia do Ensino e Educação Comparada - Faculdade de Educação da Universidade de São Paulo.

GAGNEBIN, J. M. Da escrita filosófica em Walter Benjamin. In: SILVA, M. S. Leituras de Walter Benjamin. São Paulo: Annablume, 1999. p. 61-87.

GRANGER, G. G. Por um conhecimento filosófico. Campinas: Papirus, 1989.

HABERMAS, J. Pensamiento Postmetafísico. Madrid: Taurus, 1990.

KANT, I. Textos seletos. 2. ed. Petrópolis: Vozes, 1985.

LEBRUN, G. Por que filósofo? Estudos Cebrap (São Paulo), v. 15, p.148-153, 1976.

LIPOVETSKY, G. Os tempos hipermodernos. São Paulo: Barcarolla, 2004.

LYOTARD, J. F. O Pós-Moderno explicado às crianças. 2. ed. Lisboa: Dom Quixote, 1993.

Pequena perspectivação da decadência de alguns combates minoritários a travar. In: GRISONI, D. G. Políticas da Filosofia. Lisboa: Moraes, 1983, p.9-21.

NASCIMENTO, M. M. A filosofia no $2^{\circ}$. grau: sua importância, sua especificidade. In: Textos Filosóficos. São Paulo: Secretaria do Estado da Educação de São Paulo, 1986, p. 3-12.

PEREIRA, O. P. Prefácio a uma filosofia. Revista Discurso (São Paulo), v.5, 1975.

RIBEIRO, R. J. A Universidade e a vida atual: Fellini não via filmes. Rio de Janeiro: Campus, 2003.

SILVA, F. L. Função social do filósofo. In: Textos Filosóficos. São Paulo: Secretaria do Estado da Educação de São Paulo, 1986, p.15-30.

VIRILIO, P. O espaço crítico. São Paulo: Editora 34, 1993. 